\title{
CUIDADOS NA REALIZAÇÃO DA PROPEDÊUTICA OBSTÉTRICA VISANDO A PREVENÇÃO DA INFECÇÃO HOSPITALAR EM MATERNIDADES
}

\author{
Amélia M ${ }^{\mathrm{a}}$ S. de A. Maranhão* \\ Márcia Barbieri* \\ Maria Cristina Gabrielloni** \\ Suzete Maria Fustinoni**
}

\begin{abstract}
RESUMO - O presente estudo trata do cuidado especial necessário para a realização da propedêutica obstétrica com vistas à prevenção da infecção hospitalar nas unidades de matemidade. Os procedimentos principais para este objetivo enfatizam a lavagem das mãos, anamnese, inspeção, mensuração, palpação e ausculta; o toque vaginal é considerado como um agente de alto risco para infecção. Os procedimentos realizados direcionam-se à infecção hospitalar e este estudo pretende contribuir para a atualização dos profissionais neste campo.
\end{abstract}

\begin{abstract}
The present study deals with the special care needed for the obstetrical propaedeutics performance viewing the prevention of nosocomial infection within matemity units. The main procedures for this purpose focus on hand washing, assessment, inspection, measurement, palpation, and auscultation; vaginal touch is considered to be a high risk infection agent. The procedures carried out are directed towards nosocomial infection, and this study intends to contribute for the practitioners' updating in this field.
\end{abstract}

\section{INTRODUÇÃO}

Nas últimas três décadas tem sido grande a abordagem científica dada ao problema das infecções hospitalares.

Segundo definição estabelecida pelo "Center for Diseases Control", referendada pelo MINISTÉRIO DA SAÚDE ${ }^{1}$ através da Portaria 196/83, é caracterizado como infecção hospitalar, ou nosocomial, ou institucional, qualquer infecção adquirida após internação do paciente e que se manifeste durante a mesma ou após a alta, quando puder scr relacionada com a hospitalização.

Quando o período de incubação do micro-organismo for desconhecido e não houver evidência clínica ou laboratorial de infecção no paciente ao ser admitido, é considerado infecção hospitalar toda a manifestação clínica de infecção, a partir de 72 horas após a admissão. Entretanto, se houver procedimentos diagnósticos ou terapêuticos, que levem ao desencadeamento de uma infecção, esta será considerada como hospitalar, mesmo antes de 72 horas. ${ }^{1,16}$

Já a infecção comunitária, ou não hospitalar, é caracterizada como aquela que foi constatada, ou estiver em período de incubação, no ato da admissão do paciente, desde que não relacionada com internação anterior no mesmo hospital.

$\mathrm{O}$ custo e as despesas por infecções hospitalares são onerosos, tanto para o paciente quanto para a Instituição que o atende. Segundo estimativas da American Hospital Association, essas infecções são responsáveis por dias adicionais de hospitalização, prolongando a permanência média do paciente no Hospital de 5 a 10 dias, sendo de 500 dólares o custo médio diário por paciente.

As infecções hospitalares podem ter origem endógena, exógena e exógena-endógena. As endógenas são "causadas por agentes potencialmente patógenos encontrados na microbiota normal humana do próprio paciente, em virtude de um desequilíbrio entre esses micro-organismos e os mecanismos de def esa anti-infecciosa do doente" ${ }^{18}$ As exógenas "são as infecções

\footnotetext{
* Enfermeira. Prof essor Assisistente do Departamento de Enfermagem da Escola Paulista de Medicina.

** Enfermeira. Especialista e m Enfermagem Obstétrica. Mestranda em Enf., área de concentração: Enf ermagem Obstétrica.
} 
cujos agentes atingem o hospedeiro a partir de um reservatório ou fonte externa". ${ }^{15}$ São causadas por "micro-organismos da microbiota humana normal, transferidos de outros pacientes ou do ambiente hospitalar, ou por patógenos primários do homem ou de animais, transmitidos por outro doente, ou por microorganismos encontrados no solo, em vegetais ou na água" ${ }^{18}$. A infecção hospitalar exógena-endógena é "aquela em que o paciente, primeiramente colonizado pela microbiota normal humana presente no ambiente, torna-se infectado por ela. Neste caso, o processo infeccioso não é provocado por bactérias sensíveis, mas por bactérias resistentes selecionadas na própria Instituição"18.

Embora admita-se que a maioria das infecções hospitalares sejam de origem endógena ${ }^{18}$ e de ação preventiva difícil, o número de infecções hospitalares evitáveis é significativo ${ }^{23}$. Um estudo recente do "Center for Diseases Control" constatou que os hospitais que possuíam um programa ef etivo no controle de infecções hospitalares obtiveram uma redução de cerca de um terço na incidência daquelas de origem endógena ${ }^{23}$.

No Brasil, poucos hospitais tinham um programa efetivo de controle de Infecções Hospitalares até a publicação da Portaria n ${ }^{\circ} 196$ de 24 de junho de 1983 '. Esta Portaria recebeu maior atenção em decorrência da morte de Tancredo Neves em 1985, antes de tomar posse no cargo de Presidente da República, para o qual havia sido eleito pelo Congresso Nacional. Após a primeira internação cirúrgica, o Presidente eleito teve complicações, sendo identificada uma bactéria típica de infecção hospitalar.

Estima-se que no país, de 5 a $15 \%$ dos pacientes internados contraem infecções hospitalares. $\mathrm{O}$ dado certo ninguém sabe, pois não existem estatísticas nacionais a respeito, havendo apenas dados aproximados, relativos aos maiores hospitais do país, situados nos grandes centros urbanos. "Da extrapolação de tais dados, pode-se avaliarquecerca de $50 \%$ dos pacientes que contraem infecções hospitalares morrem, o que poderia significar, no mínimo, de 50 a 100 mil óbitos anuais"'3.

Em unidades de ginecologia e obstetrícia, as pacientes que se internam estão sujeitas a procedimentos invasivos "que abrem vias de acesso aos tecidos estéreis do organismo, para microbiota normal própria, para a dos profissionais da saúde" ${ }^{10}$ e, portanto, correm o risco de adquirir infecções durante o período de intemação. Nessas áreas, os dados sobre a incidência de inf ecções hospitalares são escassos e raros em nosso país ${ }^{19}$. Os poucos dados existentes sobre as taxas dessas inf ecções em maternidades, talvez não sejam fidedignos porque, muitas vezes, a puérpera não retorna ao serviço, procurando recursos mais próximos de sua casa em casos de complicações, principalmente nas grandes metrópoles. As infecções hospitalares adquiridas em toco-ginecologia são normalmente causadas pela "microbiota normal da paciente, não de excluindo, todavia, a possibilidade dos agentes serem bactérias selecionadas no ambiente hospitalar, inoculadas nos pacientes pela manipulação incorreta das mesmas"19.

Sabe-se que não existe índice zero de infecções hospitalares porém, através de medidas profiláticas, pode-se aceitar as que são preveníveis. É menos oneroso prevenir do que tratar, porque a infecção exige um consumo elevado de antibióticos caros e um prolongamento do tempo de internação.

"A profilaxia das infecções toco-ginecológicas hospitalares constitui complementação inevitável da assistência materno-infantil, que as autoridades sanitárias, dc todos os países, se propõem a prestar, atendendo à recomendação da Organização Mundial de Saúde"19.

As pessoas que procuram os hospitais estão sujeitas a adquirir inf ecções que poderiam ter sido evitadas se não houvesse uma confiança exagerada na antibioticoterapia, desleixo na limpeza, assepsia e antissepsia favorecendo o desenvolvimento de microorganismos resistentes.

Se os cuidados básicos de profilaxia das infecções hospitalares não fossem colocados em segundo plano, muitos pacientes ficariam livres de sofrimentos desnecessários, seriam diminuídos os custos elevados pelo tratamento que recebem e a vida dessas pessoas não seria colocada em risco.

No trabalho da equipe do saúde, o Serviço de Enfermagem é o mais envolvido com as atividades que contribuem para prevenir a infecção hospitalar. Para atingir este objetivo, uma enfermagem eficiente deve basear o seu trabalho em novos conhecimentos, preocupar-se com os aspectos epidemiológicos desta inf ecção, fundamentados em coleta e análise de dados estatísticos para implementar medidas preventivas.

Os profissionais da área de saúde são responsáveis pela realização de procedimentos, dentro do contexto hospitalar, que podem ser um reservatório de micro-organismos diversificados. Desta forma, a possibilidade de ocorrerem infecções torna-se maior e, a cada dia que passa, o controle e a prevenção da infec- 
ção hospitalar assumem papéis mais importante. É uma necessidade sentida pelos profissionais da saúde e começa a ser uma exigência da população..

Infelizmente, não existe ainda uma responsabilidade consciente de todos os profissionais da saúde sobre como atuar corretamente dentro do Hospital. Os pacientes e os visitantes, também, não recebem essas informações.

Os cuidados preconizados para a prevenção da infecção hospitalar devem ser tomados em qualquer lugar em que a paciente é assistida na maternidade. Os procedimentos devem ser bem definidos, tomando-se medidas com o objetivo de reduzir, ao mínimo, a possibilidade de se constituírem em veículos de infecções.

Diante dos aspectos destacados sobre a infecção hospitalar em geral, e em toco-ginecologia e, considerando que alguns procedimentos realizados na assistência à gestante ou à parturiente podem ser responsáveis por estas infecções em maternidades, decidiuse realizar este trabalho com os seguintes objetivos:

- identificar na propedêutica obstétrica os procedimentos com gestantes e parturientes que podem estar relacionados com a ocorrência de infecção hospitalar em matemidade;

- aplicar conhecimentos de prevenção da infecção hospitalar ao descrever os cuidados específicos na realização destas ações.

\section{A PROPEDÊUTICA OBSTÉTRICA NO CONTEXTO DA INFECÇÃO HOSPITALAR}

O local em que será realizada a propedêutica obstétrica deve conter o menor número de micro-organismos. Os procedimentos na realização da anamnese, inspeção, mensuração, palpação, ausculta e toque, devem ser bem definidos, tomando-se todas as medidas com o objetivo de reduzir ao mínimo, a possibilidade de se constituírem em veículos de infecções.

O profissional de saúde que atua em qualquerárea da matemidade deve saber que a lavagem das mãos se destaca como elemento fundamental de prevenção da infecção. Portanto, a execução da propedêutica deve ser precedida da lavagem das mãos.

A LAVAGEM DAS MÃOS reduz em até $80 \%$ as infecções cruzadas.

Na pele das mãos, os micro-organismos encontrados podem ser classificados em flora transitória e residente. Para $Z_{A N O N}{ }^{20}$, a microbiota transitória resulta do contato da pele com o meio ambiente. É extremamente variável, não aderente ao epitélio e, portanto, facilmente transferida para outros indivíduos e fômites. Esta flora pode ser adquirida pelo contato direto, assim sendo, as mãos podem ser transportadoras de agentes causadores das infecções hospitalares. Como essa microbiota transitória não se encontra firmemente aderida à pele, pode ser removida através de uma lavagem das mãos com água e sabão.

A flora residente é composta de micro-organismos que vivem e se multiplicam na pele, aderindo à superfície das células epiteliais, podendo ser mantido um equilíbrio perfeito com o hospedeiro. Em geral, a lavagem das mãos não remove a população estável da flora residente, pois esta só pode ser removida parcial e temporariamente, pela descamação celular natural ou por escovação, cuja técnica encontra-se posteriormente descrita, e as bactérias, que fazem parte desta população estável, podem ser inativadas pelos antissépticos $^{21}$

A lavagem das mãos, considerada eficaz na prevenção das infecções hospitalares, deve ser realizada

- ao chegar ou sair do Hospital;

- entre contatos com diferentes pacientes;

- antes da aplicação de procedimentos invasivos;

- ao tossir, ao espirrar;

- antes e depois do contato com ferimentos;

- antes e após ir ao banheiro;

- sempre que se julgar necessário.

Para a remoção da matéria orgânica das mãos que inclui óleos, gorduras, protcínas, secreções e excretas, é necessário lavá-las, utilizando sabões e detergentes que são compostos tenso-ativos que dissolvem as gorduras, mantendo suas partículas em estado de emulsão estável na água, juntamente com as impurezas. Desta forma, a matéria orgânica é facilmente removida das mãos pelo enxágue ${ }^{20}$.

Para que a lavagem das mãos atinja seus objetivos de remoção da matéria orgânica, inclusive da flora transitória, deve ser observada a técnica rigorosa:

- abrir a torneira;

- molhar as mãos;

- aplicar sabão ou detergente;

- friccionar as mãos por, no mínimo, 30 segundos em toda a face da palma e do dorso, nos espaços 
interdigitais, articulações, unhas e extremidades dos dedos;

- enxaguar em água corrente, no sentido das mãos para os cotovelos, mantendo sempre as mãos e os braços mais elevados que os cotovelos, de forma que a água escoe dos dedos para o pulso;

- secar as mãos;

- fechar a torneira com papel toalha para que não ocorra a recontaminação imediata das mãos ${ }^{7}$. Tomar o cuidado de não encostar a roupa na pia ou mesmo as mãos depois de lavadas, pois, neste local, pode haver descamação celular natural onde poderão estar presentes bactérias da flora transitória e da residente.

Se for utilizado o sabão em barra ou sabonete, estes devem ser colocados em saboneteira vazada para que a água drene e não permita o crescimento de bactérias, contaminando as mãos de quem os manipulem. No uso do sabão líquido, o recipiente, quando vazio, deve ser lavado e seco antes de ser reabastecido para o uso ${ }^{4}$.

Em vários hospitais brasileiros, devido a problemas de construções sem planejamento para o trabalho técnico, o profissional da saúdo vê-se impossibilitado de lavar as mãos com a freqüência necessária. Nesta circunstância, a lavagem periódica pode ser substituída pela fricção das mãos com 3 a $5 \mathrm{ml}$ de solução, sendo os produtos mais indicados:

- clorhexidine a $0,5 \%$ em álcool etílico a $70 \%$, que proporciona ação residual devido a clorhexidine, antisséptico que age sobre fungos e bactérias, apresenta baixo potencial de irritabilidade e de fotossensibilidade ao contato, sendo muito pouco absorvido pela pele íntegra e menos irritante, devido à presença de um emoliente e um detergente não iônico ${ }^{6}$;

álcool a $70 \%$ com glicerina a $2 \%$, que se justifica pela observação de que a friç̧ão com álcool sobre a pele, até secar, é um processo de descontaminação tão eficiente quanto a lavagem durante 30 a 60 segundos com água e sabão ${ }^{21}$.A glicerina age como emoliente evitando o ressecamento da pele causado pelo álcool.

Durante a realização da ANAMNESE é mantido um diálogo entre o profissional e a paciente que requer uma certa proximidade.

Sabe-se que a "flora da cavidade oral é diversificada e que a saliva contém $10^{8}$ bactérias $/ \mathrm{ml}$ e as placas dentais $10^{11}$ bactérias"1'4. Em cada palavrapronuncia- da, lança-se cerca de 4375 microorganismos. O "contato de agentes inf ecciosos com o hospedeiro pode ser por projeção de gotículas, onde partículas de muco ou gotículas de saliva, expelidas diretamente ao espirrar, tossir ou falar, constituem uma modalidade de transmissão por contato direto" ${ }^{18}$. "Os micro-organismos transportados pelo ar em núcleos de gotículas, têm características físicas que permitem sua transmissão"12 porém "raramente atingem distâncias superiores a dois metros e, quando não alcançam um indivíduo, depositam-se sobre superfícies horizon-

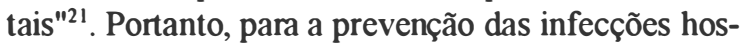
pitalares por projeção de gotículas é necessário que o profissional trate os dentes e faça higiene oral adequada pois a microbiota oral se altera qualitativamente na ausência de cuidados. Deve-se também afastar o profissional que apresentar infecções em vias aéreas superiores, pois "também pode ser um reservatório de micro-organismos, responsáveis por alguns surtos"13. É recomendado também fazer uma desinfecção com álcool a 70\% nas superfícies a cada troca de plantão para a retirada de micro-organismos que se depositaram sobre as superfícies horizontais.

A INSPEÇÃO é um exame visual destinado à observação pormenorizada e focalizada em áreas particulares do corpo. Neste método propedêutico, a única etapa que implica em cuidados para a prevenção da infecção hospitalar, é a inspeção dos órgãos genitais externos, quando se entreabre os grandes lábios. Esta etapa é feita por ocasião do toque onde serão descritos os cuidados.

A MENSURAÇÃO da altura uterina e da circunferência abdominal, tem como objetivo contribuir para a avaliação da idade gestacional, do tamanho do feto, ocorrência de poli-hidrâmnio ou gemelaridade.

Para a mensuração, utiliza-se fita métrica que entrará em contato com a pele íntegra da paciente. Após a medida, deve-se fazer uma desinfecção da fita métrica com algodão embebido em álcool a $70 \%$ no sentido distal para o proximal ou pode ser realizada uma limpeza com água e sabão, quando a fita for lavável. Após desinfecçào ou limpeza, apoiá-la em local limpo para o próximo uso. Deve-se cuidar para que a fita métrica seja de material que resista a esta desinfecção ou limpeza.

A PALPAÇÃO é um procedimento que tem a finalidade de reconhecer a situação, a apresentação e posição fetal, altura da apresentậãa, ocorrência de poli-hidrâmnio e gemelaridade.

É um procedimento inócuo, seus informes são seguros e tem, sobre o toque, a vantagem de evitar a 
possível contaminação que pode ocorrer através do exame vaginal.

O cuidado para a prevenção da infecção hospitalar na palpação é a lavagem das mãos ou a friç̧ão das mãos com 3 a $5 \mathrm{ml}$ de solução de clorhexidine a $0,5 \%$ em álcool etílico a $70 \%$, ou solução de álcool a 70\% com glicerina a $2 \%$ pelo examinador, na impossibilidade de lavagem das mãos.

Em nosso meio, a AUSCULTA obstétrica é realizada mais comummente com o estetoscópio de Pinard de material plástico e mais raramente de madeira ou metal. Pode também ser executada pelo Sonar Doppler que, embora se ja um meio mais seguro, nem sempre é acessível, devido ao custo.

O estetoscópio de Pinard mantém contato com a mão e o pavilhão auricular do examinador e com o abdome da gestante. Após a ausculta, deve-se fazer uma desinfecção deste instrumento com algodão embebido em álcool a $70 \%$ friccionando por 30 segundos, ou pode ser realizada uma limpeza com água e sabão, quando o material do estetoscópio de Pinard for lavável.

O transdutor do Sonar Doppler mantém contato com a mão do examinador e com a pele íntegra do abdome da paciente e, seria necessário, portanto, uma desinfecção ou limpeza após cada uso. Devido ao tipo de material não pode ser realizada a limpeza com água e sabão e sim uma desinfecção com algodão embebido em álcool a $70 \%$, friccionando em um único sentido por 30 segundos.

O TOQUE é um procedimento invasivo, pois representa risco infeccioso, que varia em função dos cuidados de assepsia e antissepsia durante a sua realização. Tem por objetivo avaliar a elasticidade do períneo, a permeabilidade e a rugosidade da vagina, as condições dos fundos-de-saco vaginais, o esvaecimento, a dilatação, a espessura e a elasticidade do colo $^{22}$, a presença e as características da bolsa das águas, o diagnóstico da apresentação e posição, a altura da apresentação, as características do ângulo sub-púbico da arcada púbica, das espinhas ciáticas, do sacro e do cóccix.

A técnica preceitua que se deve realizar o toque com as mãos rigorosamente lavadas e revestidas de luvas esterilizadas, entreabrindo-se a vulva com 0 polegar e o mínimo, protegendo o dedo indicador e o médio que vão ser introduzidos na vagina ${ }^{8,9,10}$,

Ao se introduzir os dedos suavemente pela vagina, deve-se ter em mente que "a vulva e a vagina exibem uma microbiota maior e mais diversificada do que a pele, e normalmente, o útero, o ovário e as trompas não são colonizados" ${ }^{\prime 19}$. Desta forma, poderão estar sendo conduzidos, de forma ascendente, microorganismos pafogênicos no canal de parto. Após a dequitação, a ferida placentária estará exposta a esses micro-organismos, podendo ocorrer as chamadas infecções hospitalares endógenas, que podem ser causadas pela maioria das bactérias que residem no corpo humano, quer sejam da flora normal ou não. De um modo geral, os microorganismos patogênicos podem ser considerados oportunistas porque, quase sempre, só expressam sua atividade patogênica quando o hospedeiro of erece condições apropriadas ${ }^{14,17}$.

As bactérias também podem penetrar no hospedeiro através do contato entre a mucosa e os dedos de examinador. O toque vaginal é traumatizante e potencialmente infectante devendo, portanto, ser reduzido ao mínimo necessário, tendo-se o cuidado de executá-lo, obedecendo, rigorosamente, todas as regras de assepsia, colhendo o máximo de informações para evitar repetições desnecessárias ${ }^{2,19}$.

Os cuidados preconizados para a realização do toque são variáveis. Existem profissionais que antes de realizarem o toque usam somente como medidas de precaução, para prevenir a infecção, luvas esterilizadas e soluções antissépticas de iodóforos (PVPI tópico), que têm ação germicida residual, não queimam, não mancham os tecidos, não interferem no metabolismo e raramente provocam reações alérgicas. Um inconveniente apontado para o seu uso é a cor, que pode ser conf undida com mecônio.

Outra solução antisséptica que está sendo utilizada nos Serviços de Obstetrícia é a clorhexidine a 0,5\%, que tem ação imediata sobre bactérias e fungos, apresentando um bom poder de ação residual e baixo poder de irritabilidade 6 .

GREENHILL ${ }^{5}$ preconiza a prática da limpeza, na realização do toque, com água e sabão.

$\mathrm{O}$ examinador não deve tocar a área anal e os dedos só deverão entrar em contato com o introito vaginal e a sua mucosa ${ }^{5}$, para evitar contaminação e subseqüente infecção ${ }^{2}$.

Quando houver rotura de membranas, não deve ser realizado, pois constitui um fator de risco no infecção amniótica, trazendo " repercussão do processo inflamatório sobre o organismo materno e fetal devido a infecção ascendente da cavidade ovular a partir dos germes existentes na vagina ${ }^{11}$. Desta forma, em suspeita de bolsa rota deve ser realizado o exame especular. 
O CONTROLE DA DINÂMICA UTERINA é realizado com o examinador colocando sua mão no fundo do útero. No controle da dinâmica uterina durante 10 minutos, deve ser observada a freqüência das contrações, duração e intensidade de cada uma e o tônus uterino no intervalo entre as mesmas.

A dinâmica uterina pode ser caracterizada como um procedimento não invasivo e o examinador, como regra, deve proceder a lavagem das mãos ou, na impossibilidade deste procedimento, fazer a ficção das mãos com 3 a $5 \mathrm{ml}$ de solução de clorhexidine a $0.5 \%$ em álcool a $70 \%$, ou solução de álcool a $70 \%$ com glicerina a $2 \%$, antes e após a sua realização..

\section{CONCLUSÕES}

O presente trabalho sobre os cuidados na realiza- ção da propedêutica obstétrica, visando a prevenção da infecção hospitalar em Maternidades, permite as seguintes conclusões:

- na assistência à gestante ou à parturiente, a prevenção da infecção hospitalar constitui uma complementação indispensável à assistência materno-infantil;

- a lavagem das mãos, o uso correto de antissépticos e a execução correta de determinados procedimentos da assistência desde o pré-natal até o puerpério são fatores fundamentais para a prevenção da infecção hospitalar em Maternidades;

- dentre os elementos que compõem a propedêutica obstétrica, o toque é o único procedimento invasivo com risco infeccioso para a gestante, parturiente e/ou puérpera.

\section{REFERÊNCIAS BIBLIOGRÁFICAS}

1 BRASIL - Ministério da Saúde. Portaria ${ }^{\circ}$ 196, de 24 de junho de 1983. Anexo V.

2 BRIQUET, R. Semiologia Obstétrica. In:-----Obstetricia Normal. 3. ed. São Paulo: Sarvier, 1981, cap.13, p.191-230.

3 FERRARI, B. T. Inf ecção hospitalar a tragédia do Brasil. Rev. Bras. 'de Clinica e Terapêtica, 14 (5): 147-153, maio, 1985.

4 GONTIJO FILHO, P.P., ARMÔA, G.R.G.Antissépticos, lavagem de mãos e a prevenção de inf ecções hospitalares. Rev. Bras. Cir., 74 (3):143-146,1984.

5 GRENHILL, J.P., FRIEDNAW, E.A. Início e evolução clínica do parto. In: ----- Obstetricia. Rio de Janeiro: Interamericana, 1976, cap.14, p.184-197.

6 L.M.FARMA - Farmácia de manipulação. Manual de esterilização e desinfecção. São José dos Campos. 1989, p.1-15.

7 LEME, M.T.C.L. Antissepsia., In:-----Flashes em controle de infecção. Curitiba: Relisul, 1990, cap.3, p.64-69

8 OXORN, H. Útero e Vagina. In: -...-.-Trabalho de parto. 5. ed. São Paulo: Roca, 1989, cap.4, p.15-20.

9 Exame da paciente. In: -----Trabalho de parto. 5 ed. São Paulo: Roca, 1989, cap.9, p.65-78.

10 POMBO, R.M.G., RAMALHO,J.D. Controle de procedimentos invasivos. In: ZANON, U., NEVES, J. Infecções hospitalares. Prevenção, deagnóstivo e tratamento. Rio de Janeiro: Medsi, 1987, seção 1, cap.29, p.811-829.

11 REZENDE, J. de., DEODATO FILHO, J. Mecanismo de parto. In: -..--Obstetricia. 4. ed. Rio de Janeiro: Guanabara Koogan, 1982, cap.14, p.278-288.

12 SÃo CAMILO, S.B. Epidemiologia de Infecção. In: -----Controle de infecção no hospital. 3. ed. São Paulo: 1985, cap.2, p.6-8.

13 SÃO PAULO (ESTADO). Secretaria de Estado da Saúde. Infecções incisionais. Informes técnicos, 1 (4): 1-3, dez, 1989. Gepro de inf ecção hospitalar.
14 TRABULSI, L.R., TOLEDO, M.R.F. de Flora normal do corpo humano. In: TRABULSI. Microbiologia 2ed. São Paulo: Atheneu, 1989, cap.6, p.43-58.

15 TRABULSI, L.R., SILVA, N.P. Esterilização e desinfecção. In: TRABULSI.Microbiologia. 2 ed.São Paulo: Atheneu, 1989, cap. 16, p.99-102.

16 ZANON, U. Sistema parasito ambiente-hospedeiro. In: ZANON, U., NEVES,J. Infeç̧ões hospitalares. Prevenção, diagnóstivo e tratamento. Rio de Janeiro: Medsi, seçãolI, cap. 4 , p.59-63.

17 ., LORJAN, V. Mecanismos de def esa antiinfecciosa. In: ZANON, U., NEVES, J. Infeç̧ões hos pitalares. Prevenção, diagnóstico e tratamento. Rio de Janeiro: Medsi,1987, seçãoII, cap.7, p.165-186.

18 , AMADO, O.L. Inf ecções hospitalares tocoginacológicas. In: ZANON, U., NEVES, J. Infeç̧ões hospitalares. Prevenção, diagnóstico e tratamento. Rio de Janeiro, Medsi, 1987, seçãoIII, cap.13, p.389-408.

19 . Profilaxia geral da supuração da faixa cirúrgica. In:-----Infecções hospitalares. Prevenção, diagnóstico e tratamento. Rio de Janeiro: Medsi, 1987, seção V, cap.48, p.789-810.

20 . Degermação e Antissepsia. In ZANON, U., NEVES, J. Infecções hos pitalares. Prevenção, diagnóstico e tratamento. Rio de Janeiro: Medsi, 1987, seção V, cap.32, p.895-917.

21 ZIEGEL, E.E., CRANLEY, M.S. Anatomia Obstétrica. O trajeto e o objeto. In: -----Enfermagem Obstétrica. 8. ed. Rio de Janeiro: Interamericana, 1985, cap. 16, p.293-312.

22 . Curso clínico e mecanismo de parto e do parto. In: -----Enfermagem Obstétrica. 8. ed. Rio de Janeiro: Interamericana, 1985, cap.17, p. 313-329.

23 WEY, S.B. et alii. Infecção hospitalar. In: --.--Considerações gerais sobre um programa de infecção hospitalar. trabalho de pós-graduação apresentado à Disciplina de Doença Infecto Parasitária do Departamento de Medicina da Escola Paulista de Medicina. São Paulo,1988,p.1-51. 